\title{
Humanização da assistência ao parto: opinião dos acadêmicos de enfermagem
}

RESUMO | Objetivo: investigar a opinião dos acadêmicos de enfermagem sobre a humanização da assistência ao parto. Método: estudo descritivo, exploratório com abordagem qualitativa. Para a análise dos depoimentos, utilizou-se a técnica de análise de conteúdo proposta por Bardin12. A coleta de dados ocorreu no mês de junho de 2017, no Departamento de Enfermagem da Universidade Federal de Pernambuco (UFPE). A população estudada constituiu-se em discentes da Graduação em Enfermagem da UFPE. A seleção dos participantes foi casual na qual as pesquisadoras realizaram pessoalmente o convite, sendo incluídos alunos que expressaram o desejo de participar. Resultados: evidenciou-se que dentre as três categorias principais, centradas: 1. no protagonismo da mulher, 2. na humanização dos cenários da assistência ao parto e 3. em ações educativas tanto dos profissionais quanto da parturiente. Observou-se também, diante das respostas colhidas, a existência de subcategorias que reforçam a importância das três principais. Conclusão: entende-se então que, o processo de humanização da assistência ao parto é amplo, e analisá-lo sob a perspectiva de profissionais da saúde e de estudantes de Enfermagem é um caminho.

Palavras-chaves: Enfermagem Obstétrica; Estudantes; Humanização da Assistência; Parto Normal; Parto Humanizado.

ABSTRACT | Objective: to investigate the opinion of nursing students on the humanization of childbirth care. Method: descriptive, exploratory study with a qualitative approach. For the analysis of the testimonies, the content analysis technique proposed by Bardin12 was used. Data collection took place in June 2017, at the Nursing Department of the Federal University of Pernambuco (UFPE). The studied population consisted of undergraduate nursing students at UFPE. The selection of participants was casual, in which the researchers personally made the invitation, including students who expressed the desire to participate. Results: it became evident that among the three main categories, centered: 1 . on the role of women, 2 . on the humanization of childbirth care scenarios and 3. on educational actions by both professionals and parturients. It was also observed, in view of the responses collected, the existence of subcategories that reinforce the importance of the three main ones. Conclusion: it is understood, then, that the humanization process of childbirth care is broad, and analyzing it from the perspective of health professionals and nursing students is one way.

Keywords: Obstetric Nursing; Students; Humanization of Assistance; Natural Childbirth; Humanizing Delivery.

RESUMEN | Objetivo: investigar la opinión de estudiantes de enfermería sobre la humanización del cuidado del parto. Método: estudio descriptivo, exploratorio con abordaje cualitativo. Para el análisis de los testimonios se utilizó la técnica de análisis de contenido propuesta por Bardin12. La recolección de datos tuvo lugar en junio de 2017, en el Departamento de Enfermería de la Universidad Federal de Pernambuco (UFPE). La población estudiada estuvo constituida por estudiantes de licenciatura en enfermería de la UFPE. La selección de los participantes fue casual, en la que los investigadores hicieron personalmente la invitación, incluidos los estudiantes que manifestaron el deseo de participar. Resultados: se evidenció que entre las tres categorías principales, se centró: 1. en el papel de la mujer, 2. en la humanización de los escenarios de atención al parto y 3. en las acciones educativas tanto de profesionales como de parturientas. También se observó, a la vista de las respuestas recolectadas, la existencia de subcategorías que refuerzan la importancia de las tres principales. Conclusión: se entiende, entonces, que el proceso de humanización del cuidado del parto es amplio, y analizarlo desde la perspectiva de los profesionales de la salud y estudiantes de enfermería es una vía.

Palavras claves: Enfermería Obstétrica; Estudiantes; Humanización de la Atención; Parto Normal; Parto Humanizado.

\section{Marta Maria Francisco}

Mestre em Enfermagem pela Universidade Federal de Pernambuco (UFPE); Aluna Especial do Doutorado em Enfermagem em Saúde Pública pela Escola de Enfermagem de Ribeirão Preto da Universidade de São Paulo (USP). Recife, Pernambuco (PE), Brasil. ORCID: 0000-0001-8938-9179

\section{Iara Alves Feitoza de Andrade}

Mestre em Enfermagem pela Universidade Federal de Pernambuco (UFPE); Enfermeira Especialista em Hematologia pela Universidade de Pernambuco (UPE). Recife, Pernambuco (PE), Brasil. ORCID: 0000-0003-3495-0613

\section{Liniker Scolfild Rodrigues da Silva}

Especialista em Enfermagem Obstétrica na modalidade Residência pela Faculdade de Enfermagem Nossa Senhora das Graças/ Universidade de Pernambuco (FENSG/ UPE). Sanitarista, Especialista em Saúde Coletiva na modalidade Residência pela Faculdade de Ciências Médicas (FCM)/UPE. Recife, Pernambuco (PE), Brasil. Recife, Pernambuco (PE), Brasil.

ORCID: 0000-0003-3710-851X

\section{Mirthis Cordeiro Ferreira}

Mestre em Enfermagem pela Universidade Federal de Pernambuco (UFPE). Recife, Pernambuco (PE), Brasil.

ORCID: 0000-0003-4751-8483

\section{Danielle Luiza Figuerôa de A. Aymar}

Médica graduada pela Universidade Federal de Pernambuco (UFPE); Médica pela Secretaria Estadual de Saúde do Estado de Pernambuco (SES/PE) no Hospital Otávio de Freitas (HOF). Recife, Pernambuco (PE), Brasil. ORCID: 0000-0003-4161-8483

\section{Elania Maria da Silva Simões \\ Residente em Enfermagem em Infectologia pelo Hospital Universitário Oswaldo Cruz (HUOC) pela Secretaria Estadual de Saúde do Estado de Pernambuco (SES/PE). Recife, Pernambuco (PE), Brasil.}

ORCID: 0000-0003-3328-1737

Recebido em: 16/09/2020

Aprovado em: 06/10/2020 
INTRODUÇÃO

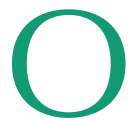
parto é um acontecimento natural e fisiológico, no passado, esta prática restringia-se ao ambiente domiciliar, assistido por parteiras ou comadres, as quais aprendiam a partejar com outras parteiras e com experiências pessoais. A mulher era o centro da assistência e a evolução natural do trabalho de parto era respeitada ${ }^{1}$.

Com a solidificação da obstetrícia como ciência ocorreram mudanças no cenário da assistência ao parto ${ }^{1}$, o que antes era um evento natural, particular e familiar passou a ser algo institucionalizado, repleto de intervenções tecnológicas, descentralizando a figura da mulher como protagonista e redirecionando essa atenção ao médico ${ }^{1}$.

Essa transformação no cenário da assistência ao parto fez com que as mulheres passassem a acreditar na necessidade de tais intervenções, e começassem a desacreditar da naturalidade do mesmo. Apesar das mudanças no cenário da assistência ao parto, na maioria dos casos, serem responsável pela diminuição das taxas de mortalidade materna e neonatal, é preciso garantir que a parturiente venha a beneficiar-se dos avanços científicos sem, no entanto, naturalizar tal fator. O profissional não deve permitir que o saber científico se sobreponha à natureza do corpo feminino ${ }^{2,3}$.

Diante disso, começaram a surgir movimentos a favor da humanização da assistência ao parto, como por exemplo, o Movimento pela Humanização do Parto e Nascimento (MHPN) no qual se busca racionalizar o uso das tecnologias, assim como reduzir o índice de cesáreas e da mortalidade materna, garantindo uma participação mais efetiva da parturiente nas decisões sobre a própria saúde e atuando durante o parto como protagonista, exercendo, em consequência disso, um papel mais decisivo e ativo durante todo o processo ${ }^{4}$. Compreendendo tais necessidades, a Organização Mundial de Saúde (OMS), em 1995, lançou o Projeto Maternidade segura que preconiza, dentre ou- tras recomendações, à humanização da assistência ao parto ${ }^{5}$.

Dos desafios encontrados pelos profissionais da saúde, ao prestar assistência ao parto de forma humanizada, atingir o equilíbrio nas práticas, de modo que estas tragam mais benefícios do que danos à parturiente, adaptando as condutas a cada uma das necessidades individuais delas, é uma tarefa complexa. De acordo com o modelo humanizado, o profissional deve permanecer com a paciente durante todo o trabalho de parto a fim de oferecer apoio psicológico e emocional, transmitir segurança, além de oferecer técnicas de relaxamento e conforto ${ }^{3,4,6}$.

$\mathrm{Na}$ busca por tornar o parto normal o mais natural e fisiológico possível, o enfermeiro obstetra tem exercido papel fundamental ao transformar o cenário de práticas intervencionista e fortalecer o modelo assistencial humanístico. Sua assistência é caracterizada por uma atuação humanizada e de qualidade, respeitando-o como algo fisiológico, reduzindo o índice de intervenções desnecessárias e de morbimortalidade. A cada dia, a presença desse profissional na assistência ao parto normal de baixo risco torna-se mais solicitada ${ }^{2}$.

A revisão de literaturas específicas evidencia que as práticas da enfermagem obstétrica, em uma casa de parto, são atribui à mulher uma postura ativa durante $\mathrm{o}$ processo de nascimento, respeitando as necessidades e desejos de cada uma delas, permitindo que as mesmas exerçam seu papel de protagonista neste cenário ${ }^{7}$.

Um estudo fora realizado em uma maternidade pública de Santa Catarina que tinha por objetivo compreender os significados atribuídos a parturiente ao processo de parir assistido pelo enfermeiro obstetra no contexto hospitalar. Nele, evidenciou-se que a assistência prestada por este profissional é caracterizada pelo respeito à feminilidade, delicadeza, permissão da liberdade de expressão e oportunidade de aprendizado, transmitindo segurança e ânimo ${ }^{8}$.

Diante do exposto, observa-se a importância do preparo dos estudantes da graduação em Enfermagem, no decorrer do curso, para que atuem de forma humanizada e respeitosa durante a assistência a mulher em todo ciclo gravídico puerperal. Surge, em consequência disso e como objetivo de investigação deste estudo, o seguinte questionamento: Qual a opinião dos acadêmicos de enfermagem sobre a humanização da assistência ao parto?

\section{MÉTODO}

O estudo utiliza-se dos métodos descritivo e exploratório com abordagem qualitativa. A metodologia qualitativa busca aspectos mais profundos, fornecendo uma análise mais detalhada. Esta torna-se, portanto, uma tentativa de compreender os significados e características situacionais, respondendo questões particulares, que envolvem o trabalho em um setor de significados, motivos, aspirações, crenças, valores e atitudes ${ }^{9}$.

A coleta de dados ocorreu no mês de junho de 2017, no Departamento de Enfermagem da Universidade Federal de Pernambuco (UFPE), Campus Recife. O curso de Graduação em Enfermagem da UFPE possui duração mínima de dez semestres e habilita o estudante a desenvolver funções assistenciais, administrativas, extensão e de pesquisa nos diversos cenários da prática profissional.

A população estudada constituiu-se de discentes do Curso de Graduação em Enfermagem da UFPE, Campus Recife. Sendo incluídos os maiores de 18 anos que aceitaram livremente participar da pesquisa. Os critérios de exclusão consistiram em alunos que não estivessem cursando nenhuma disciplina no momento da coleta de dados.

A pesquisa se deu a partir da realização de Grupo Focal, essa técnica permite a discussão do tema sugerido pelo pesquisador de forma que se possa obter opiniões dos participantes a partir da interação em grupo $^{10}$. Bastou um encontro para realizar o objetivo da pesquisa, que ocorreu por meio da saturação de dados, visto que o grupo era composto por seis 
discentes. A saturação ocorre quando os discursos apresentam conteúdos repetidos e nenhuma informação nova é acrescentada, representando um discurso comum do grupo ${ }^{11}$.

A seleção dos participantes foi feita de forma aleatória na qual as pesquisadoras realizaram pessoalmente o convite, sendo incluídos os alunos que expressaram o desejo em participar. O grupo focal foi realizado em uma sala do departamento de enfermagem, guiado por duas questões norteadoras: "Para vocês o que é humanização da assistência ao parto?" e "Como o profissional pode exercer a humanização na prática?". Os discursos foram gravados com o auxílio de aplicativo para dispositivo móvel, ao término, o material foi validado com os participantes, e posteriormente transcrito na íntegra.

Para a análise dos depoimentos, utilizou-se a técnica de análise de conteúdo proposta por Bardin ${ }^{12}$. Tal técnica é composta por três etapas: pré-análise, exploração do material ou codificação e tratamento dos resultados. Após a leitura das entrevistas, selecionaram-se os núcleos de sentido de cada uma delas. Estes deram o significado da categoria/tema que foi desenvolvida.

\section{RESULTADOS}

Os participantes eram do sexo feminino, encontravam-se na faixa etária entre 18 e 20 anos, três cursavam o $3^{\circ}$ período e outras três cursavam o $8^{\circ}$ período do curso de graduação em enfermagem. A análise das falas originou três categorias, dentre elas, duas apresentaram também subcategorias, e numeradas abaixo.

Categoria 1: Protagonismo da mulher no parto. Subcategorias: 1.1: Respeito às escolhas da mulher; 1.2: Assistência centrada na mulher.

Categoria 2: Humanização nos diversos cenários da assistência ao parto;

Categoria 3: Ações de educação como ferramenta de promoção a humanização da assistência ao parto. Subcategorias: 3.1: Promovendo a humanização por meio de ações de educação em saúde direcionadas as gestantes; 3.2: Promoção da humanização por meio da formação profissional.

Cada categoria exposta acima é demarcada, especificamente, por um conjunto de sentidos e falas, apresentando também a leitura e exposição de literaturas que embasaram e fortaleceram tais afirmativas, sendo, portanto, descritas a seguir.

Categoria 1: Protagonismo da mulher no parto

Subcategoria 1.1: Respeito às escolhas da mulher

$\mathrm{O}$ respeito à mulher foi mencionado como um meio que possibilita a decisão da parturiente junto ao profissional do que é melhor para si nesse momento tão singular. Os profissionais da saúde devem sugerir métodos facilitadores do trabalho de parto, oferecer meios de alívio da dor, orientar as melhores posições, mas a decisão cabe a gestante, a qual terá o livre direito à expressão para fazer a melhor escolha para si, sem pressões ou constrangimentos13. Inclusive, se optar por ficar acompanhada ou sozinha no momento. Como retratado nas falas abaixo:

"Que ela (mulher) escolha como quer ser, qual a posição, se vai receber ou não métodos invasivos."

"Deixar a mulher ter essas escolhas, a melhor posição para ela ter o bebê, quais os melhores métodos, se ela quer estar acompanhada, pelo marido, mãe, irmã..."

"Parto humanizado é você respeitar a vontade da mulher, do que ela quer naquele momento."

"Você (profissional) não pode impor sua vontade."

"Respeitar as escolhas que elas (mulheres) fizerem sem querer impor nada."

"Respeitar o que ela quer sem que seja algo invasivo, determinado previamente, a escolha é dela."
Subcategoria 1.2: Assistência centrada na mulher

A mulher deverá ser assistida de acordo com as próprias especificidades, o cuidado deve ser individualizado em respeito aos desejos da mesma, uma vez que ela é protagonista desse momento. Como vemos nas falas abaixo:

"... O profissional de saúde preste assistência deixando que a mulher seja a principal autora desse momento."

"Seria deixar que a mulher fosse a protagonista"

"É você respeitar o protagonismo da mulher independente de qualquer coisa."

"Você (profissional) tem que dar assistência de qualidade, adequado para aquela mulher, específico para ela, do que ela precisa."

"É acima de tudo respeitar a mulher, respeitar o corpo da muIher..."

"É deixar que a mulher seja a protagonista."

Categoria 2: Humanização nos diversos cenários da assistência ao parto

A humanização deve permear toda assistência ao ciclo gravídico puerperal, estando presente desde o planejamento familiar. A fala das participantes explicita que as boas práticas da humanização podem e devem estar presentes em todas as situações, independentemente do tipo de parto, do quadro clínico ou das escolhas da parturiente. Como observamos nas falas a seguir:

"Humanização do parto não é só no parto normal uma cesárea pode ser humanizada, um parto normal com anestesia pode ser humanizado."

"Não só no parto, desde o pré-natal, a preparação para aquela gravidez."

"Preparar o ambiente ser cal- 
mo, não ser tão frio, mais escuro."

"Fazer todas aquelas práticas que promovam o máximo de bem-estar."

Categoria 3: Ações de educação como ferramenta de promoção a humanização da assistência ao parto

Subcategoria 3.1: Promovendo a humanização por meio de ações de educação em saúde direcionadas as gestantes

O modelo de assistência pré-natal referenciado pelo Programa de Humanização no Pré-natal e Nascimento (PHPN) inclui além do atendimento individual realizado durante as consultas, as ações de educação em saúde que oferecem benefícios e acrescentam sentido mais amplo; asseguram, ainda, o vínculo com a equipe de saúde ${ }^{14}$.

A educação em saúde constitui-se como ferramenta essencial para o empoderamento das mulheres ${ }^{15}$ e assistência das mesmas. Conhecer e entender a fisiologia da gestação e do trabalho de parto permite a mulher esclarecer dúvidas e reduzir os medos e anseios, além de fornecer subsídios para que façam as escolhas em relação à assistência ao trabalho de parto e optem, também, pela antecipação do mesmo, por meio do planejamento, favorecendo escolhas conscientes, como relatado pelas participantes:

"É promover a autonomia da mulher..."

"Primeiramente, a gente informar a essas mulheres sobre esses direitos que elas têm, falar para elas das escolhas que elas têm. Falar do plano de parto"

"Deixar a mulher bem ciente de todo o processo, do que vai ocorrer."

"Orientar a mulher antes porque tem muitas que não sabem os direitos que elas possuem. Empoderamento dessa mulher."

Subcategoria 3.2: Promoção da humanização por meio da formação profissional
O discurso das participantes destacou a importância da formação profissional na humanização da assistência ao parto, a qual deve sensibilizar os alunos em relação às práticas profissionais, não sendo repassado um modelo assistencial centrado apenas na execução da técnica, mas estimulando a realização delas, respeitando as particularidades de cada indivíduo, humanizando o cuidado oferecido.

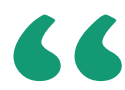

Humanizar é
acreditar que o
parto normal é
fisiológico e que
na maioria das
vezes não precisa
de qualquer
intervenção...

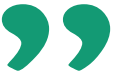

Observou-se, ainda, referência às práticas assistenciais antigas, mostrando a necessidade de atualizações para os profissionais que já se encontram no setor há mais tempo, uma vez que ocorreram muitas transformações nas recomendações a assistência obstétrica, havendo divergência quanto às práticas, das quais algumas antes consideradas benéficas não são mais recomendadas por apresentarem contraindicação.

"Trabalhar a equipe de saúde, muitas vezes a equipe não está aberta a novas condutas, então o importante é conscientizar a equi- pe de saúde, capacitações ou então palestras."

"Tem que vir da formação do profissional, é difícil mudar a cabeça de um profissional com anos de formação."

"Para isso acontecer deveria partir primeiramente do profissional, do interesse dele, para depois poder fazer essas orientações às mulheres."

\section{DISCUSSÃO}

A humanização do parto está além de práticas e técnicas, centra-se no respeito à mulher como individuo, em um momento da vida em que ela necessita de atenção e cuidados, que devem se estender à família e ao bebê, garantindo a ele o direito a um nascimento sadio e harmonioso. Esse processo deve permear todos os serviços de saúde, os quais devem estar envolvidos na humanização da assistência ao parto, de acordo com as normas técnicas e recomendações do Ministério da Saúde ${ }^{14}$.

Humanizar é acreditar que o parto normal é fisiológico e que na maioria das vezes não precisa de qualquer intervenção; saber que a mulher é capaz de conduzir o processo e que ela é a protagonista desse evento; conversar e informar a mulher sobre os procedimentos, além de pedir autorização para realizá-los, também deve fazer parte da assistência; garantir e incentivar a presença de um acompanhante escolhido por ela, para transmitir-lhe segurança e tranquilidade; promover um ambiente acolhedor, respeitando as individualidades, considerando os medos e angustias; oferecer à mulher as melhores condições e recursos disponíveis, para que se sinta acolhida e segura nesse momento tão especial; prestar assistência ao parto e nascimento seguindo as evidências científicas e os mais altos padrões de qualidade, de acordo com as Normas Técnicas e recomendações do Ministério da Saúde; permitir o contato imediato do bebê com a mãe logo ao nascer, e garantir que permane- 
çam juntos durante todo o período de internação ${ }^{16}$.

Concordando com os achados deste estudo uma pesquisa evidenciou que para os discentes de enfermagem a humanização é um estado de bem-estar, envolvendo carinho, dedicação respeito pelo outro, ou seja, considera a pessoa como um ser completo e complexo ${ }^{17}$.

No Brasil, culturalmente falando, o parto normal ainda é associado a sofrimento e violência, criando nas mulheres uma idealização de que a cesariana vai Ihes garantir a segurança de um parto sem dor $^{17}$. Somado a isso o atendimento desrespeitoso, por parte de muitos profissionais da saúde durante este procedimento, faz com que as mulheres se sintam humilhadas, optando por uma forma de nascimento que consideram mais higiênica e digna. Os maus tratos revelam preconceito, pois se dirigem, principalmente, às mulheres com menor poder aquisitivo, negras, viciadas e soropositivas ${ }^{18}$.

A prática de uma assistência humanizada, através de uma equipe multidisciplinar que orienta a parturiente $\mathrm{e}$ o/a acompanhante por meio de ações de educativas, permite que a ela se movimente livremente durante o trabalho de parto, além de disponibilizar camas especiais e adaptáveis as necessidades dela, proporcionando maior satisfação materna em relação ao parto e fortalece o vínculo familiar ${ }^{16}$.

O Parto Humanizado proporciona ao bebê e à mãe a experiência real do nascimento, permitindo também a participação do pai ou de outros familiares em tão importante momento. Fisicamente, contribui para que a mãe não fique com cicatrizes, como a da cesariana e a da episiotomia (corte vaginal), que costuma ser feita de 70 a $80 \%$ dos partos hospitalares, quando o recomendado é de no máximo $20 \%$. Não sofrer a episiotomia facilita as futuras relações sexuais e também evita o aparecimento de incontinência urinária ${ }^{19}$.

As mulheres percebem a necessidade e anseiam receber informações durante a assistência, e, ao mesmo tempo, acabam sendo multiplicadoras do conhecimento com outras gestantes, pois ao trocarem vivências e informações, geram poderosas fontes transformadoras de limitações e necessidades, adquirindo domínio sobre o corpo e o poder de decisão sobre a gravidez ${ }^{15}$.

A comunicação e informação em saúde entre profissionais e gestantes devem ser priorizadas no transcurso da assistência pré-natal em todo e qualquer atendimento, uma vez que a troca de informações e experiências pode ser a melhor forma de promover a compreensão do processo gestacional, resultando no empoderamento da mulher ${ }^{20}$.

Corroborando o resultado encontrado, um estudo que analisou as relações estabelecidas entre a mulher e a própria experiência no processo parturitivo e educativo mostrou que as envolvidas nas ações educativas apresentaram comportamento diferente das demais parturientes, uma vez que eram mais comunicativas, procuravam explicações a respeito das condutas adotadas pelos profissionais, tomavam decisões, tinham iniciativas de aceitar ou recusar procedimentos, evidenciando que a educação em saúde resulta em atitudes mais ativas por parte da mulher ${ }^{21}$.

Portanto, a criação de um espaço para trocas de experiências e vivências em grupo configura uma condição indispensável para a mobilização dos estereótipos de cada um, o que ajuda cada participante a enfrentar as situações de mudanças geradas por certo grau de distorção e medo, uma vez que tende a "re-significar" as vivências através do reconhecimento dos outros e de $\mathrm{si}^{14}$.

Promover o bem-estar é inerente ao setor da saúde, especialmente na enfermagem, visto que o enfermeiro passa mais tempo junto ao paciente. Este profissional lida diretamente com essas ações, a educação na área da saúde é um processo que acontece durante todo o desenvolvimento dessas ações/intervenções, partindo do pressuposto de que todo o indivíduo tem direito à saúde de forma integral e essa virtude se dá no momento em que o sujeito toma conhecimento dos direitos ${ }^{15}$.

Nesse contexto, observa-se ainda a necessidade de intervir junto aos profissionais da saúde na Atenção Básica, Média e de Alta Complexidade, a fim de que os mesmos possam internalizar as práticas assistenciais humanizadas ${ }^{14}$. Apesar do novo modelo curricular, a academia ainda desfruta de alguns percalços advindos de departamentos que se mantêm engessados dentro da mesma instituição ${ }^{15}$. E nesse ínterim, os profissionais que lidam mais de perto com as parturientes se percebem no direito de escolher por elas, decidindo como serão todos os procedimentos até o parto. Porém, compreende-se que eles, ainda estão arraigados a ensinamentos não personalizados, de acordo com o que lhes foi ensinado durante graduação e pós-graduação ${ }^{15}$.

À instituição cabe reavaliar esse modelo curricular e o profissional deve buscar capacitações, aperfeiçoamento, especializações, fazer questionamentos críticos sobre o que é ensinado na graduação, além de buscar novas técnicas, condutas discutidas, apresentadas e incorporadas pelo Ministério da Saúde ${ }^{15,16}$.

Percebe-se que não é fácil desprender-se de técnicas antigas ensinadas durante todo o processo formador, porém, essa transformação pode ser mais eficaz se iniciar desde a graduação, não só com mudanças curriculares, mas, sobretudo, no olhar dos docentes que são facilitadores no processo de ensino de futuros profissionais.

Desta forma, acredita-se que a humanização na assistência deva iniciar na graduação, porque é nesse processo que os alunos começam a interagir, construir conhecimentos, habilidades e práticas, desenvolvendo assim aptidões profissionais. Este se torna o momento mais oportuno para que os futuros profissionais sejam sensibilizados e motivados a fazer uma reflexão acerca dos vários conteúdos aprendidos.

\section{CONCLUSÃO}


A discussão acerca da humanização da assistência ao parto normal, na perspectiva das estudantes entrevistadas do Curso de Graduação de Enfermagem, evidenciou pontos importantes, mesmo nas falas daquelas que ainda não haviam experienciado vivências no setor de práticas em obstetrícia, emergindo temas extremamente relevantes tais como: o comportamento do profissional de saúde no processo de humanização da assistência ao parto normal; o respeito desse profissional à mulher e intervenções de educação em saúde dos profissionais a fim de esclarecer dúvidas da paciente desde o pré-natal e empoderamento da mesma.
Este estudo pode mostrar que as estudantes de Enfermagem, associam a humanização da assistência ao parto normal ao respeito à decisão da parturiente, com ênfase no protagonismo dela no parto, o direito de escolha de permanência ou recusa de acompanhante, à decisão de onde e como o parto será realizado, direito a segurança, conforto e conhecimentos de como ocorrerão os processos.

Diante desses achados, vislumbra-se à educação em saúde como uma porta de entrada a assistência ao parto humanizado, caracterizado pelo processo de mudança, evidenciado através das práticas realizadas pelos profissionais da saúde, principalmente, médicos e enfermeiros.

O processo de humanização da assistência ao parto é amplo, e analisá-lo sob a perspectiva de profissionais da saúde e de estudantes de Enfermagem é um caminho, mas existem muitos outros envolvidos, principalmente se a instituição de ensino for considerada como propagadora de práticas e processos de atendimento à saúde. Compreende-se, de tal maneira, que as concepções acerca do processo por parte dos professores e dos profissionais envolvidos seriam extremamente válidas para melhor abordagem do ensino, aprendizagem e prática da assistência humanizada ao parto normal.

\section{Referências}

1. Portella MO. Ciência e costume na assistência ao parto [Tese]. Recife: Universidade Federal de Pernambuco; 2017. 262 s. Disponível em: https:// repositorio.ufpe.br/bitstream/123456789/29485/1/TESE\%20Mariana\%20 de\%200liveira\%20Portella.pdf Programa de Pós-Graduação em Sociologia. 2. Zanardo GLP, Uribe MC, Nadal AHR, Habigzang LF. Violência Obstétrica No Brasil: Uma Revisão Narrativa. Psicol. Soc. 2017, vol.29, e155043.https:// doi.org/10.1590/1807-0310/2017v29155043.

3. Souza SRRK, Gualda DMR. A Experiência Da Mulher E De Seu Acompanhante No Parto EmUma Maternidade Pública. Texto Contexto Enferm, 2016; 25(1):e4080014. https://doi.org/10.1590/0104-0707201600004080014. 4. Kottwitz F, Gouveia HG, Gonçalves AC. Via de parto preferida por puérperas e suas motivações. Esc. Anna Nery. 2018; 22(1): e20170013. https://doi.org/10.1590/2177-9465-ean-2017-0013.

5. Santos HFL, Araujo MM. Políticas de Humanização ao pré-natale parto: uma revisão da literatura. Revista Científica FacMais. 2016; 6(2): 54-64. Disponivel em: http://revistacientifica.facmais.com.br/wp-content/uploads/2016/07/Artigo-6-POL\%C3\%8DTICAS-DE-HUMANIZA\%C3\%87\%C3\%830-AO-PR\%C3\%89-NATAL-E-PARTO.pdf

6. Cardoso DC, Barbosa MD, Mendes NH, Silva AP, Bonfim NQ, Pereira WS et al. A importância do parto humanizado: uma revisão bibliográfica. REAS.2020;(41):e2442.https://doi.org/10.25248/reas.e2442.2020

7. Reis TLR, Padoin SMM, Toebe TFP, Paula CC, Quadros JS. Autonomia femininano processo de parto e nascimento:revisão integrativa da literatura. RevGaúchaEnferm. 2017 mar;38(1):e64677.http://dx.doi.org/10.1590/19831447.2017.01.64677.

8. Vieira DR, Apolinario JA. A Violência Obstétrica Na Compreensão De Mulheres Usuárias Da Rede Pública De Saúde Do Município De Lins. [TCC]; São Paulo: Centro Universitário Católico Salesiano Auxilium; 85f. Disponível em: http://www.unisalesiano.edu.br/biblioteca/monografias/61050.pdf 9. Lakatos EM; Marconi MA. Metodologia Científica. $7^{\text {a }}$ ed. São Paulo: Atlas, 2017.

10. Mendonça I, Gomes MF. Grupo Focal: Instrumento De Coleta De Dados Na Pesquisa Em Educação. Cad. Ed. Tec. Soc., 2017, 10(1):52-62. http://dx. doi.org/10.14571/cets.v10.n1.52-62

11. Minayo MCS. Amostragem E Saturação Em Pesquisa Qualitativa:Consensos E Controvérsias. Revista Pesquisa Qualitativa. São Paulo: 2017, 5(7):0112. Disponível em: https://edisciplinas.usp.br/pluginfile.php/4111455/mod_ resource/content/1/Minayosaturacao.pdf

12. Bardin, L. Análise do conteúdo. São Paulo: Edições 70, 2011. 280 p.

13. Brasil. Ministério da Saúde. Secretaria de Ciência, Tecnologia e Insumos
Estratégicos. Departamento de Gestão e Incorporação de Tecnologias em Saúde.Diretrizes nacionais de assistência ao parto normal: versão resumida [recurso eletrônico] / Ministério da Saúde, Secretaria de Ciência, Tecnologia e Insumos Estratégicos, Departamento de Gestão e Incorporação de Tecnologias em Saúde. - Brasília: Ministério da Saúde, 2017. 51 p

14. Brasil. Ministério da Saúde. Humanização do parto e do nascimento / Ministério da Saúde. Universidade Estadual do Ceará. - Brasília: Ministério da Saúde, 2014.465 p.: il. - (Cadernos HumanizaSUS; v. 4)

15. Tostes NA, Seidl EMF. Expectativas de gestantes sobre o parto e suas percepções acerca da preparação para o parto. Temas psicol. [Internet]. 2016; 24(2): 681-693.http://dx.doi.org/10.9788/TP2016.2-15.

16. Martins FL, Silva BO, Carvalho FLO, Dalmo MC, Paris RLP, Guidi Junior LR, et al. Violência Obstétrica: Uma expressão nova para um problema histórico. Revista Saúde em Foco, 2019; (11): 413-423. Disponível em: http://portal. unisepe.com.br/unifia/wp-content/uploads/sites/10001/2019/03/034_VIOL\%C3\%8ANCIA-OBST\%C3\%89TRICA-Uma-express\%C3\%A30-nova-para-um-problema-hist $\%$ C3\%B3rico.pdf

17. Freitas FDS, Ferreira MA. Saberes de estudantes de enfermagem sobre a humanização. Rev. Bras. Enferm.2016 Apr; 69(2): 282-289. https://doi. org/10.1590/0034-7167.2016690211i.

18. Santos, BM. A percepção do discente de enfermagem sobre a humanização: um estudo fenomenológico em Merleau-Ponty. 2018. 130 f. Dissertação (Mestrado Acadêmico em Ciências do Cuidado em Saúde) - Universidade Federal Fluminense, Niterói, 2018. Disponível em: https://app. uff.br/riuff/handle/1/8981

19. Possati AB, Prates LA, Cremonese L, Scarton J, Alves CN, Ressel LB. Humanização do parto: significados e percepções deenfermeiras. Escola Anna Nery. 2017; 21(4): e20160366. https://doi.org/10.1590/2177-9465ean-2016-0366.

20. Silva SN, Santos MAP, Campos NPS, Souza C, Gonzaga MFN, Pereira RSF et al. A Importância do Pré-Natal na Prevenção da Toxicemia Gravídica e o Papel do Enfermeiro. Revista Saúde em Foco, 2017;(9): 8-16. Disponivel em: http://portal.unisepe.com.br/unifia/wp-content/uploads/ sites/10001/2018/06/003_a_importancia_do_pre_natal_na_prevencao_ da_toxicemia.pdf

21. Jardim MJA, Silva AA, Fonseca LMB. Contribuições do Enfermeiro no Pré-Natal para a Conquistado Empoderamento da Gestante. Rev Fund Care Online. 2019.11(n. esp):432-440. http://dx.doi.org/10.9789/21755361.2019.v11i2.432-440 